\title{
Relationship between Yersinia enterocolitica antibody level and bacterial shedding after challenge in previously immunized pigs
}

\author{
ALEKSANDRA PLATT-SAMORAJ', WOJCIECH SZWEDA ${ }^{l}$, ANDRZEJ K. SIWICKI \\ ZBIGNIEW PROCAJEO ${ }^{l}$, ELŻBIETA MIKULSKA-SKUPIEN' ${ }^{1}$, AGATA BANCERZ-KISIEL ${ }^{l}$, \\ ANNA SZCZERBA-TUREK ${ }^{l}$, KINGA SYCZYEO $O^{l}$
}

${ }^{1}$ Department of Epizootiology, Faculty of Veterinary Medicine, University of Warmia and Mazury in Olsztyn, Poland

${ }^{2}$ Department of Microbiology and Clinical Immunology, Faculty of Veterinary Medicine, University of Warmia and Mazury in Olsztyn, Poland

\begin{abstract}
Asymptomatic carriers of Yersinia enterocolitica are often found in pigs which are the main reservoir and source of human infection. Carrying of that bacteria is usually connected with a long-term shedding and microbiological contamination of the environment. Thus, the aim of this study was to determine the effect of immunization with a suspension of selected strains of $Y$. enterocolitica on the duration of pathogen shedding in experimentally infected pigs.

Fifteen pigs were divided into three groups, two experimental and one control. Immunizing suspension was administered subcutaneously in doses of $2 \mathrm{ml}$ (group I) and $5 \mathrm{ml}$ (group II) with the density of $2.7 \times 10^{9}$ CFU/ml of formaldehyde inactivated cells suspended in phosphate-buffered saline in two injections within an interval of two weeks. Pigs were experimentally infected with a $10 \mathrm{ml}$ dose of a pathogenic strain of Y. enterocolitica O:3 with the density of $2.7 \times 10^{9} \mathrm{CFU} / \mathrm{ml}$ two weeks after immunization.

Subcutaneous immunization stimulated higher antibody levels in group II, which was administered a higher inoculant dose of $5 \mathrm{ml}$ suspension with the density of $2.7 \times 10^{9} \mathrm{CFU} / \mathrm{ml}$. In this group, shedding was not reported in two out of five pigs, and the period of pathogen excretion was shorter in comparison with group I and the control group. Experimental immunization against infections caused by Y. enterocolitica did not prevent pathogen shedding, but merely limited the intensity and duration of bacterial excretion.
\end{abstract}

Key words: Yersinia enterocolitica, immunization, challenge.

(Centr Eur J Immunol 2013; 38 (2): 203-207)

\section{Introduction}

Pigs are the main reservoir and source of Yersinia $(Y$.) enterocolitica infection [1-4]. The pathogen easily enters and colonizes the porcine organism, but clinical symptoms of the disease are rarely observed in this species. Asymptomatic carriers usually continue to shed the pathogen for a long time, posing a health threat to other animal species and humans. Carriers of $Y$. enterocolitica are found in all age groups, but finishing pigs are most susceptible to infection [5-8].

Frequent infections of pigs with pathogenic $Y$. enterocolitica strains cause long-term colonization of palatine tonsils, and then this is the reason for contamination of meat during the slaughter process. For many years, efforts have been made to increase the effectiveness of $Y$. enterocoliti$c a$ detection in food and prevent the contamination of pork carcasses in abattoirs $[1,2,5,9]$. The pathogen has numerous transmission pathways, which is why all attempts to eliminate them from pig herds had failed and no effective methods for avoiding infection of animals have been developed to date. For this reason, the role of veterinary services in preventing $Y$. enterocolitica infections in humans is limited to detecting the presence of the microorganism in animal products and prevent the contamination of pork carcasses with the intestinal contents $[1,10,11]$. 
The pathogenesis of infections caused by $Y$. enterocolitica and the immunological processes in the host's body have not been fully elucidated $[2,12]$. The majority of in vivo studies concerning immunization against $Y$. enterocolitica were performed on a mice model, and they failed to provide a detailed recognition of processes in pigs, which plays a key role in the epidemiology of the infection [1316]. Experimental immunization of pigs could produce a wider picture of the reactions encountered in this species where the risk of the infection should be eliminated or reduced first of all for epidemiological reasons. In view of the above, we prepared the experimental suspension containing selected and highly immunogenic $Y$. enterocolitica strains isolated from internal organs of aborted fetuses and rectal swabs from sows. The objective of this study was to determine the effect of immunization with a suspension of selected $Y$. enterocolitica strains on the duration of pathogen shedding in comparison to the antibody levels in experimentally infected pigs and to search for methods that effectively prevent or minimize the negative consequences of $Y$. enterocolitica infections in pigs.

\section{Material and methods}

A total of 60 strains were selected based on their effect on phagocyte activity determined by Respiratory Burst Activity/Potential Killing Activity (RBA/PKA) assays [17-19] and the activity of T-cells whose proliferation response under exposure to $Y$. enterocolitica was assessed by MTT (Mitogen Transformation Test) [20, 21]. Only strains showing the highest level of immunogenicity measured by RBA/PKA and MTT were selected for the inoculum. The principles and criteria for isolate selection were described in the previous paper [22].

\section{Animals}

The experiment was performed on 15 hybrid PIC pigs with an average body weight of $48 \mathrm{~kg}$, negative in serological and bacteriological tests for the presence of $Y$. enterocolitica antibodies and bacteria in rectal swabs. The animals were randomly divided into three groups and placed in isolated compartments.

All experimental activities were performed in compliance with Polish and international legal standards stipulating the conditions and procedures for conducting experiments on animals. The study protocol was approved by the Local Ethics Commission (No. 24/N).

\section{Immunization}

The inoculum was prepared from a 48-hour culture of selected $Y$. enterocolitica strains on trypticase soy agar (Difco) at $25^{\circ} \mathrm{C}$. The animals were administered various doses of the $Y$. enterocolitica suspension with the density of $2.7 \times 10^{9} \mathrm{CFU} / \mathrm{ml}$ of formaldehyde inactivated cells suspended in phosphate-buffered saline (PBS, $\mathrm{POCH}$, Poland).
Formaldehyde was added to the suspension to produce a final concentration of $0.1 \%$. The suspension was stored at $4{ }^{\circ} \mathrm{C}$ for around 24 hours. Inactivated bacterial cells were centrifuged to remove formaldehyde, and suspended in sterile PBS according to the method described by Nakajima et al. [16].

The inoculum was administered subcutaneously in doses of $2 \mathrm{ml}$ (group I) and $5 \mathrm{ml}$ (group II) in two injections within an interval of two weeks. The third group of animals was the control and was administered PBS subcutaneously in line with the above protocol.

An in vivo evaluation was carried out after the animals had been experimentally infected with a $10 \mathrm{ml}$ dose of a pathogenic strain of $Y$. enterocolitica $\mathrm{O}: 3$ with the density of $2.7 \times 10^{9} \mathrm{CFU} / \mathrm{ml}$ two weeks after immunization.

The animals' health status, appetite, body temperature and weight gains were monitored regularly throughout the experiment.

\section{Antibodies}

Blood samples for serological tests were collected once a week from the cranial vena cava. The samples were centrifuged to separate the serum which was frozen at $-20^{\circ} \mathrm{C}$ and stored for further analysis. The levels of antibodies specific of the $Y$. enterocolitica Yop antigen (Yersinia outer protein) were determined by the ELISA as described in the previous paper [22].

\section{Bacteriological examinations}

Rectal swabs for bacteriological examinations were collected daily in the first week after infection, and then once a week over a period of seven weeks.

Y. enterocolitica was cultured on ITC (irgasan, ticarcillin and potassium chlorate, Merck) and CIN-Agar (Difco) media. After 48 hours of incubation in ITC broth at $22^{\circ} \mathrm{C}$, the pathogen was cultured on CIN agar and incubated for a further 48 hours at $28^{\circ} \mathrm{C}$.

\section{Statistical analysis}

The results were processed statistically using Fisher's Least Significant Difference (LSD) test and Tukey's Honestly Significant Difference (HSD) test in the STATISTICA 6.0 application.

\section{Results}

The first and booster immunization had no effect on the clinical picture or body weight gains of the inoculated animals. No clinical symptoms or significant differences in body weight gains were observed between groups after experimental infection, with the exception of body temperature which was higher in the control group on the first day post infection (dpi) and remained elevated in the course of the successive seven days. 
The fastest and strongest immune response after challenge to the oral administration of $Y$. enterocolitica was observed in the control group already in the first week post infection (wpi). In the third wpi, antibody levels were similar in all groups and they remained high and similar until the end of the experiment (Fig. 1). The levels of antibodies for $Y$. enterocolitica during the experimental inoculation of pigs were measured by the ELISA, and the results were presented in our previous paper [22].

In the first wpi, bacterial shedding was observed in all animals in group I and the control group as well as in three out of five pigs in group II. In successive weeks, pathogens were isolated only from animals of group I and control group in the second wpi (Fig. 2).

\section{Discussion}

According to a report of the European Food Safety Authority (EFSA), Y. enterocolitica is the third most important cause of gastrointestinal diseases in humans transmitted by contaminated foodstuffs [11]. For this reason, continued research efforts are needed to at least minimize the number of infections caused by the pathogen. The complex pathogenesis of $Y$. enterocolitica, our incomplete knowledge of immunological processes and numerous transmission pathways obstruct the search for satisfactory solutions. At present, the most effective methods of disease prevention include the observance of stringent sanitary and epidemiological standards and the elimination of reservoirs of $Y$. enterocolitica, for example through vaccination.

The majority of experimentally induced infections and inoculations against $Y$. enterocolitica were carried out on animal species other than pigs [14-16, 23]. The course of the disease in mice, rabbits or dogs is not always identical to that observed in pigs, which are the most frequent natural host for $Y$. enterocolitica. Many research papers delivered contradictory results, probably due to species' resistance to $Y$. enterocolitica infections and different course of infection, therefore, they had a limited relevance to studies involving a porcine model.

In a study of dogs experimentally infected with $Y$. enterocolitica, Hayashidani et al. [23] observed that antibody levels did not increase significantly despite the fact that the animals had been infected with a highly virulent strain of serotype O:8. In immunized mice, experimental infection by intra-peritoneal and intra-gastrical administration of the pathogen did not intensify the immune response, but it completely inhibited pathogen shedding with feces in mice infected intra-peritoneally and shortened shedding periods in mice infected intra-gastrically in comparison with control animals.

In our study, the production of antibodies was clearly enhanced by both immunization and experimental infection, although the animals were immunized with a biotype $1 \mathrm{~A}$ strain which is generally regarded as a virulent one [22].

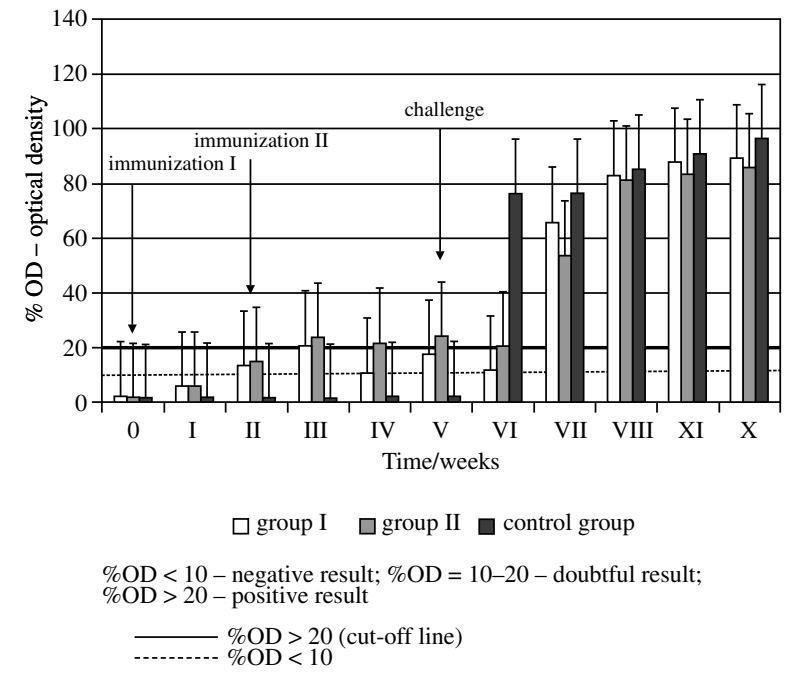

Fig. 1. Yersinia enterocolitica anti-Yop IgG levels measured with the ELISA in pigs after experimental immunization and challenge

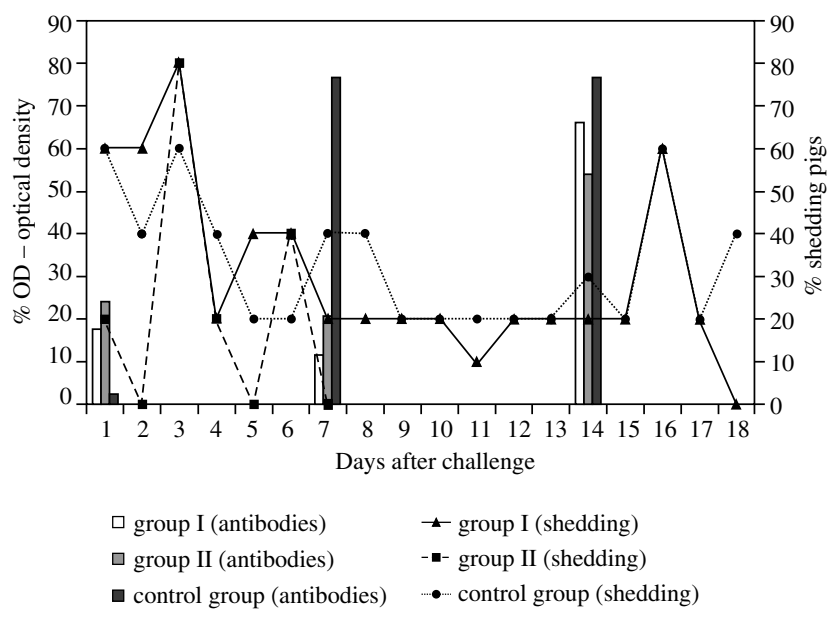

Fig. 2. Shedding of $Y$. enterocolitica in immunized and experimentally infected pigs with antibody levels background

In RBA/PKA and MTT tests, all strains in the inoculum emerged as highly immunogenic, what probably contributed to the intensity of the immune response measured by serum antibody levels. Contrary to the results reported by Nakajima et al. [16], pathogen shedding was not completely inhibited despite the use of highly immunogenic strains, but a higher and more sustained increase in body temperature in the control group than the experimental groups could suggest that the inoculum had a certain effect on the course of infection.

Subcutaneous immunization stimulated higher antibody levels in group II which was administered a higher inocu- 
lant dose of $5 \mathrm{ml}$ suspension with the density of $2.7 \times 10^{9}$ $\mathrm{CFU} / \mathrm{ml}$. In this group, shedding was not reported in two out of five pigs, and the period of pathogen excretion was shorter in comparison with group I and control group. The above points out to a correlation between antibody levels and the inhibition or reduction of bacterial shedding.

Carter et al. [13] also carried out their studies based on a mouse model and obtained results similar to Nakajima et al. [16]. These authors observed that the use of immune serum effectively prevented per os infections, while live and inactivated vaccines were also effective when administered orally. These vaccines also prevented the excretion of bacteria with feces in mice that had been infected per os. In animals infected intraperitoneally, the time of pathogen release from the liver, spleen and blood was shortened. With agglutinin titers of $1: 320$ or higher, bacteria were not excreted in feces. The cited authors noted that serum antibodies play an important role in the prevention of parenteral infections caused by the studied pathogen. Their results were not validated by our findings or the observations made by Uchida et al. [15], which showed that serum antibodies had no significant effect on the course of the disease caused by per os infection with $Y$. enterocolitica. Mice infected intragastrically excreted bacteria with feces even at agglutinin titers of $1: 320$ and higher.

In our experiment, the effectiveness of inoculation was evaluated following the oral administration of $Y$. enterocolitica, which is the natural way of infection in pigs, although the inoculum was administered subcutaneously. In commercial pig breeding, the preferred method of vaccination is by injection to guarantee that all animals receive the appropriate dose. Oral administration does not offer such certainty. In infections caused by pathogens such as $Y$. enterocolitica, both humoral and local cellular immunity play an important role in immune processes. In the discussed case, local immune mechanisms seem to play a more important role, which could explain the incomplete effectiveness of subcutaneous immunization. Infections caused by Salmonella spp., a pathogen that shares similar pathogenic mechanisms with $Y$. enterocolitica, can be effectively controlled in poultry with the use of oral as well as parenteral vaccines $[24,25]$. The above suggests that an equally effective vaccine could be developed against $Y$. enterocolitica. Inoculant doses with higher density could provide improved results. The above is validated by the differences in antibody levels observed in both experimental groups in correlation with shedding results. Reference data supporting the determination of an optimal inoculant dose for pigs were not found in published sources. The described criteria for the selection of inoculant strains have not been used in previous studies. Therefore, further work is needed to determine the appropriate inoculant dose for pigs.

It may be concluded that immunization against infections caused by $Y$. enterocolitica did not prevent pathogen shedding, but solely limited the intensity and duration of bacterial excretions. The results of other studies aiming to develop an effective vaccine against $Y$. enterocolitica prove that the discussed pathogen is not an easy target. Despite the high immunogenicity of $Y$. enterocolitica observed in in vitro studies, an immune response is very difficult to be elicited in vivo. It may take a long time to develop a fully effective vaccine, but the incidence of infections caused by $Y$. enterocolitica in humans can be minimized by reducing bacterial shedding in connection with introducing non-specific preventive measures. The results of our study and the epidemiological situation of yersiniosis necessitate the search for new methods of preventing $Y$. enterocolitica infections in pigs, including immunization.

\section{The authors declare no conflict of interest.}

\section{References}

1. Fredriksson-Ahomma M, Björkroth J, Hielm S, et al. (2000): Prevalence and characterization of pathogenic Yersinia enterocolitica in pig tonsils from different slaughterhouses. Food Microbiol 17: 93-101.

2. Bottone EJ (1999): Yersinia enterocolitica: overview and epidemiologic correlates. Microbes Infect 1: 323-333.

3. Fenwick S (1997): Domestic animals as potential sources of human Yersinia infection. Surveillance Wellington 24: 2, 3-5.

4. Jakubczak A, Platt-Samoraj A, Siemionek J, et al. (1993): Występowanie pałeczek $\mathrm{z}$ rodzaju Yersinia u zwierząt hodowlanych, domowych, dzikich oraz ryb pochodzących z województwa olsztyńskiego. Med Weter 49: 301-303.

5. Bowman AS, Glendening C, Wittun TE, et al. (2007): Prevalence of Yersinia enterocolitica in different phases of production on swine farms. J Food Prot 70: 11-16.

6. Korte T, Fredriksson-Ahomaa M, Niskanen T, et al. (2004): Low prevalence of yadA-positive Yersinia enterocolitica in sows. Foodborne Pathog Dis 1: 45-52.

7. Johanessen GS, Kapperud G, Kruse H (2000): Occurrence of pathogenic Yersinia enterocolitica in Norvegian pork products determined by a PCR method and a traditional culturing method. Int J Food Microbiol 54: 75-80.

8. Gurtler M, Alter T, Kasimir S, et al. (2005): Prevalence of Yersinia enterocolitica in fattening pigs. J Food Prot 68: 850-854.

9. Bhaduri S, Weslez I (2006): Isolation and characterization of Yersinia enterocolitica from swine feces recovered during the National Animal Health Monitoring System Swine 2000 Study. J Food Prot 69: 2107-2112.

10. Thibodeau V, Frost EH, Quessey S (2001): Development of an ELISA procedure to detect swine carriers of pathogenic Yersinia enterocolitica. Vet Microbiol 82: 249-259.

11. Osek J, Wieczorek K (2012): Food-borne zoonoses and their etiological agents in the EFSA report for 2010. Życie Wet 87: 363-472.

12. Jakubczak A, Platt-Samoraj A, Siemionek J, et al. (1995): Badania nad etiopatogenezą jersiniozy zakażonych doświadczalnie świń. Med Weter 51: 33-35.

13. Carter PB, MacDonald TT, Collins FM (1979): Host responses to infection with Yersinia enterocolitica. Contrib Microbiol Immunol 5: 346-350. 
14. Toyos JR, Diaz R, Hardisson C (1991): Protection of mice against parenteral and oral infection with Yersinia enterocolitica. Microbiol Immunol 76: 289-298.

15. Uchida I, Kaneko K, Hashimoto N (1982): Cross-resistance to fecal excretion of Yersinia enterocolitica and Yersinia pseudotuberculosis in mice by oral vaccination of viable cells. Infect Immun 36: 837-840.

16. Nakajima R, Kaneko K, Hashimoto N (1984): Protection against the lethal effect and arthritogenic capacity of Yersinia enterocolitica O:3 for mice. Jpn J Vet Sci 46: 721-727.

17. Secombes CJ (1990): Isolation of salmonid macrophages and analysis of their killing activity. Tech Fish Immunol 1: 137-145.

18. Siwicki AK, Anderson DP (1993): Nonspecific defence mechanisms assay in fish: II. Potential killing activity of neutrophils and macrophages, lysozyme activity in serum and organs. Fish Diseases Diagnosis and Prevention's Methods. IFI Olsztyn, FAO-Project GCP/INT/526/JPN, 105-112.

19. Mosmann T (1983): Rapid colorimetric assay for cellular growth and survival: application to proliferation and cytotoxicity assays. J Immunol 52: 67-74.

20. Siwicki AK, Krzyżanowski J, Bartoszcze M, et al. (1998): Adjuvant properties of killed Propionibacterium avidum KP40 in vaccination of dogs against canine parvovirosis. Dtsch Tierärztl Wschr 105: 186-190.

21. Rook GA, Steele J, Umar S, et al. (1985): A simple method for the solubilization of reduced NBT, and its use as a colorimetric assay for activation of human macrophages by gammainterferon. J Immunol Methods 82: 161-167.

22. Platt-Samoraj A, Szweda W, Siwicki AK, et al. (2012): Effect of experimental immunization of pigs with a suspension of Yersinia enterocolitica selected strains on changes in serum IgG levels. Centr Eur J Immunol 37: 96-102.

23. Hayashidani H, Kaneko K, Sakurai K, et al. (1995): Experimental infection with Yersinia enterocolitica serovar 0:8 in beagle dogs. Vet Microbiol 47: 1-7.

24. Deguchi K, Yokoyama E, Honda T, et al. (2009): Efficacy of a novel trivalent inactivated vaccine against the shedding of $\mathrm{Sal}$ monella in a chicken challenge model. Avian Dis 53: 281-286.

25. Barrow BA (2007): Salmonella infections: immune and nonimmune protection with vaccines. Avian Pathol 36: 1-13. 